\title{
Improving the Power Quality by MLCl type DSTATCOM
}

\author{
P. Manoj Kumar \\ EEE Department, \\ PSRCMR College of Engineering, \\ Vijayawada, INDIA.
}

\author{
Y. Sumanth \\ EEE Department, \\ RVR \&JC College of Engineering, \\ Guntur, INDIA.
}

\author{
S. N. V. Ganesh \\ EEE Department, \\ V.R.Siddhartha Engineering College \\ Vijayawada, INDIA
}

\begin{abstract}
This paper proposes multilevel inverter type DSTATCOM for mitigating voltage sag at the load side. Cascaded H-bridge configuration for multilevel inverter with advanced phase shifted pulse width modulation technique is presented. Voltage sags are generated by faults the distribution feeder. First addresses with the three-phase 5-level cascaded multi level inverter and second addresses with the three-phase 7-level cascaded multi level inverter based on the shunt active power filter for mitigating the voltage disturbances. The proposed multilevel topology is simulated using MATLAB. The simulation results of the Fivelevel and Seven-level cascaded multilevel inverters are compared in different aspects.
\end{abstract}

\section{Keywords}

MLCI (Multilevel Cascaded Inverter), DSTATCOM Distribution static compensator, (VSC) Voltage Source Converter, THD (Total Harmonic Distortion) mitigation.

\section{INTRODUCTION}

Voltage sags are one of the most dominating power quality assets, which dragged the attention of many researchers as the sensitivity of loads are increasing due extensive usage of power electronic devices. Fault at distribution level, sudden increase of loads, motor starting are some of the causes of the voltage sags. Such sudden variations of voltage are undesirable for sensitive loads. These undesirable voltage sags can be mitigated by connecting controlled devices either in series or shunt to the load. A few of such devices are dynamic voltage restorer (DVR) and DSTATCOM (Distribution Static Compensator). Both these devices require voltage source converters to satisfactory operation. Many topologies have been proposed in recent past for voltage source converters.

Multilevel inverter has drawn attention of many researchers. There are three topologies of multilevel inverters-cascaded, flying capacitor and diode clamped, each having its own advantages in various applications. Cascaded $\mathrm{H}$-Bridge multilevel inverter is one of the popular converter topologies used in high-powermedium-voltage (MV) drives. H-Bridge cascaded inverter [1] is one of the popularly used converter topology. The cascaded inverter type dynamic voltage restorer with neural control strategy is proposed [2]. The CHB inverter using 5-multilevel topology offers the following advantages.

1) Its structure will be simple and requires fewer components.

2) Simplicity of structure so the packaging layout is much easier.

3) To reaches high voltage and reduce harmonics by their own structure. Generates multistep staircase voltage waveform similar to pure sinusoidal output voltage by increasing the number of levels.
A new PWM-based control scheme has been implemented to control the electronic values in the two-level VSC used in the DSTATCOM [3-4] various control strategies have been proposed for voltage source PWM converters mainly [5-10] The Multilevel inverters require advanced PWM strategies like level shift, phaseshift or phase deposition. Among these PWM strategies phaseshifted PWM is described in this paper.

The paper is divided as per the following sections. Section-I gives the overview of the total project. Section-II presents the description of DSTATCOM. Modulation strategy is described in section-III. Section-IV \& V depicts the description of the test system and simulation results. Finally conclusions are presented in section VI.

\section{Shunt voltage controller DSTATCOM}

The principle of shunt voltage controller is Fig1. The actual controller has the same configuration as the series controller. But instead of injecting the voltage difference between the load and the system, a current is injected which pushes up the voltage at the load terminals. The load voltage during the sag is the superposition of voltage due to the system and the voltage change due to controller. A DSTATCOM does not contain any active power storage and thus only injects or draws reactive power. Limited voltage sag mitigation is possible with the injection of reactive power, but active power is needed if both magnitude and phase angle of the pre-event voltage needs to be kept constant. A DSTATCOM consist of a Seven-level voltage source converter (VSC), an isolated dc energy sources and coupling transformer connected in shunt to the distribution network. The dc voltage across the storage device in to a set of three-phase ac output voltage by using VSC converters. These voltages are in phase and coupled with the ac system through the reactance of the coupling transformer. A multifunction topology which can be drawn from VSC connected in shunt with the ac system.

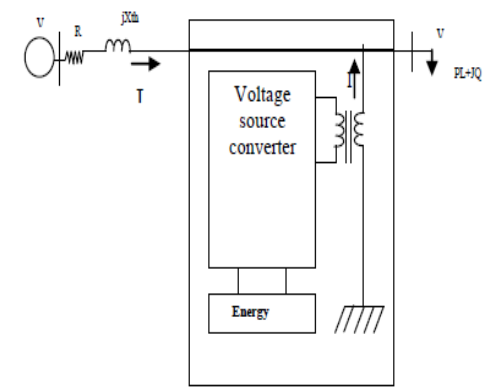

Fig 1: Schematic diagram of DSTATCOM

The multifunction topology can be achieved from VSC connected in shunt with the ac system which can be used for up to three quite distinct purposes. 
1) Power factor correction

2) Current harmonics elimination

3) Voltage regulation and compensate of reactive power Fig- 1 the shunt injected current $I_{\text {sh }}$ corrects the voltage sag by adjusting the voltage drop across the system impedance $\mathrm{Z}_{\mathrm{th}}$. The value of $I_{s h}$ can be controlled by adjusting the output voltage of the converter. The shunt injected current Ish can be written as

$$
\begin{gathered}
\mathrm{I}_{\mathrm{Sh}}=\mathrm{IL}_{\mathrm{L}}-\mathrm{IS}=\mathrm{I}_{\mathrm{L}}-\frac{\mathrm{V}_{\text {th }}-\mathrm{V}_{\mathrm{L}}}{\mathrm{Z} \text { th }} \ldots . . . .(1) \\
I \operatorname{sh} \angle \eta=I L \angle-\theta-\frac{V_{t h}}{Z_{\text {th }}} \angle \delta-\beta+\frac{\mathrm{V}_{L}}{\mathrm{Z}_{\text {th }}} \angle-\beta
\end{gathered}
$$

The complex power injection of the DSTATCOM can be expressed as

$$
\mathrm{S}_{\mathrm{sh}}=\mathrm{V}_{\mathrm{L}} \mathrm{I}^{*} \mathrm{sh}
$$

In DSTATCOM the voltage sag correction depends on the value of $\mathrm{Z}_{\mathrm{th}}$ (or) fault level of the load bus. The desired voltage correction can be achieved without injected any active power in to the system. When $I_{\text {sh }}$ minimized, the same voltage correction can be achieved with minimum apparent power injection in to the system.

\section{Controller}

The aim of the control scheme is to maintain constant voltage magnitude at the point where a sensitive load is connected, under system disturbances. The control system only measures the r.m.s voltage at the load point, i.e., no reactive power measurements are required. The VSC switching strategy is based on a sinusoidal PWM technique which offers simplicity and good response. Since custom power is a relatively low-power application, PWM methods offer a more flexible option than the Fundamental Frequency Switching (FFS) methods favored in FACTS applications. Besides, high switching frequencies can be used to improve on the efficiency of the converter, without incurring significant switching losses. The controller input is an error signal obtained from the reference voltage and the value r.m.s of the terminal voltage measured. Such error is processed by a PI controller the output is the angle $\delta$, which is provided to the PWM signal generator. It is important to note that in this case, indirectly controlled converter, there is active and reactive power exchange with the network simultaneously: an error signal is obtained by comparing the reference voltage with the r.m.s voltage measured at the load point. The PI controller process the error signal generates the required angle to drive the error to zero, i.e., the load r.m.s voltage is brought back to the reference voltage.

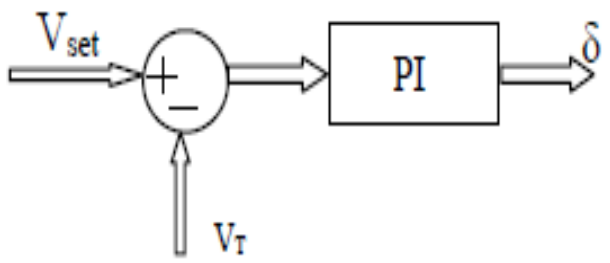

Fig 2: PI Controller for DSTATCOM

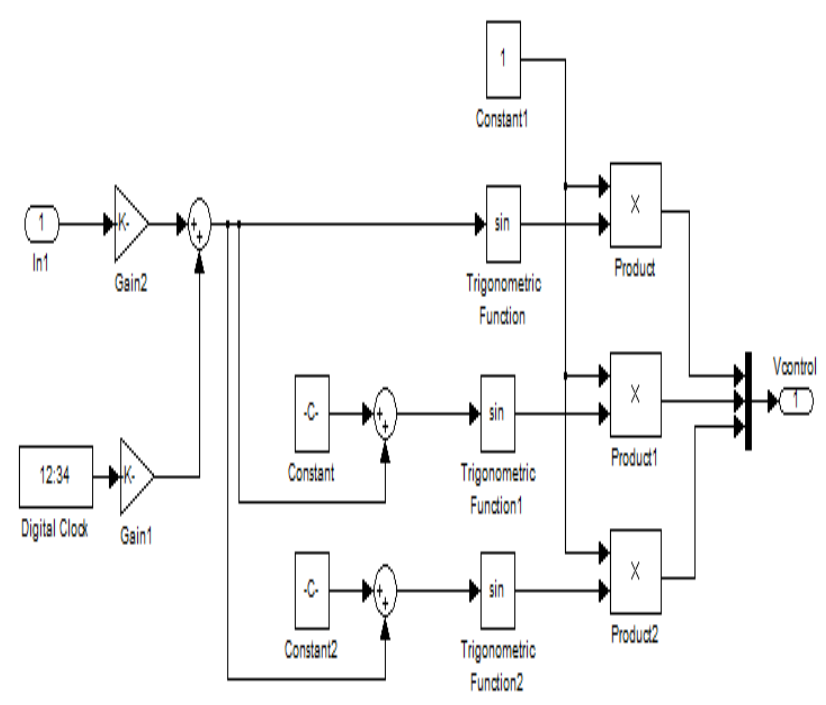

Fig 3: Generation of reference control signals for PWM controller

\section{Modulation Strategy}

Usually stair case modulation is commonly used for cascaded $\mathrm{H}$ bridge converters. For SCM, the switching instants of each module are calculated offline to attenuate certain harmonics In that case dc link voltage has to be varied in accordance to the desired ac output voltage. Due to bulk dc link voltage dynamic response slows down. As the voltage sag duration ranges from half cycle to 30 cycles, fast dynamic response is required for the DSTATCOM application. Based on this consideration, Phase shifted PWM modulation scheme is adopted to maintain a relatively constant dc link voltage while achieving the fast dynamic response required of the output voltage by varying modulation index Multilevel inverters require carrier based modulation schemes due to higher levels. The carrier-based modulation schemes for multilevel inverters are classified as phase-shifted and level-shifted modulations. Multilevel inverter with $\mathrm{m}$ voltage levels requires $(\mathrm{m}-1)$ triangular carriers. In the phase-shifted multicarrier modulation, all the triangular carriers have the same frequency and the peak-peak amplitude with phase shift between any two adjacent carrier waves given by

$$
\phi_{c r}=\frac{360^{\circ}}{(m-1)}
$$

The sinusoidal signal $\mathrm{V}_{\text {control }}$ is phase-modulated by means of the angle $\alpha$.

$$
\begin{aligned}
& \text { i.e., } \quad V a=\sin (\omega t+\delta) \\
& V b=\sin (\omega t+\delta-2 \pi / 3) \\
& V c=\sin (\omega t+\delta+2 \pi / 3)
\end{aligned}
$$

The modulated signal Vcontrol is compared against a phase shifted triangular signals in order to generate the switching signals for the VSC valves. The Fig 4 shows the pulses for one phase for 7-level. The main parameters of the phase shifted PWM scheme are the amplitude modulation index of signal, and the frequency modulation index of the triangular signal. 

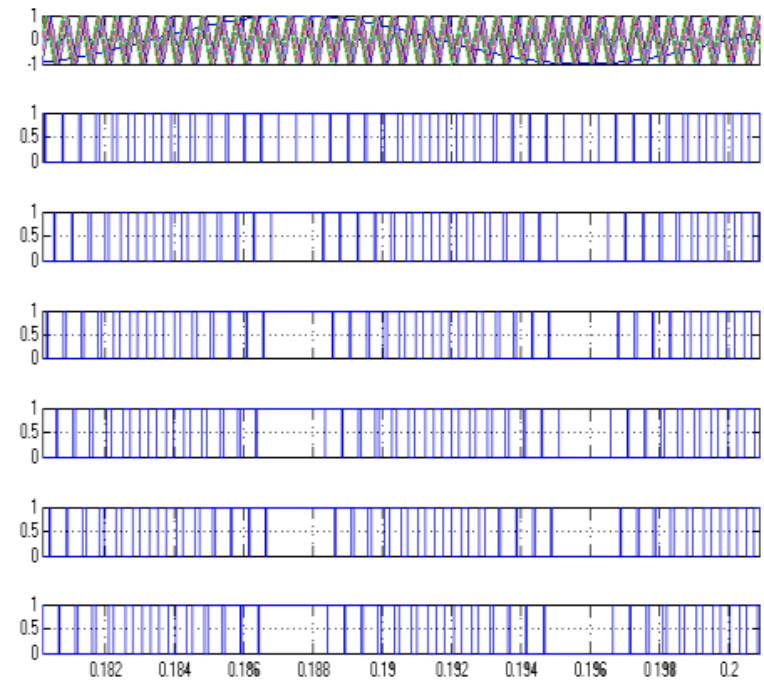

Fig 4: Phase-Shifted PWM pulses for one phase for 7-level

The amplitude index is kept fixed at $1 \mathrm{pu}$, in order to obtain the highest fundamental voltage component at the controller output.

$$
\mathrm{M}_{\mathrm{a}}=\frac{\mathrm{V}_{\text {control }}}{\mathrm{V}_{\text {tri }}}=1 \mathrm{p} . \mathrm{u}
$$

Where Vcontrol is the peak amplitude of the control signal $\mathrm{V}_{\text {tri }}$ is the peak amplitude of the triangular signals. The switching frequency is set at $2000 \mathrm{~Hz}$. The frequency modulation index is given by

$$
M f=f s / f 1
$$

Where flis the fundamental frequency

The modulating angle is applied to the PWM generators in phase A. The angles for phases B and C are shifted by 2400 and 1200 , respectively. It can be seen in that the control implementation is kept very simple by using only voltage measurements as the feedback variable in the control scheme. The speed of response and robustness of the control scheme are clearly shown in the simulation results. The voltage level and switching state of the 7level CHB (Cascaded H-bridge inverter) multi level inverter is as shown in the following tables.

Table 1. Voltage level \& switching state of 7-level multilevel inverter

\begin{tabular}{|c|c|c|c|c|c|c|}
\hline $2 \mathrm{E}$ & 1 & 1 & 1 & 0 & 0 & $2 \mathrm{E}$ \\
\hline & 0 & 0 & 1 & 0 & 0 & $2 \mathrm{E}$ \\
\hline $\mathrm{E}$ & 1 & 0 & 1 & 1 & $E$ & 0 \\
\hline & 1 & 0 & 0 & 0 & $E$ & 0 \\
\hline & 0 & 1 & 1 & 0 & $-E$ & $2 \mathrm{E}$ \\
\hline 0 & 0 & $\overline{0}$ & 0 & 0 & 0 & 0 \\
\hline & 0 & 0 & 1 & 1 & 0 & 0 \\
\hline & 1 & 1 & 0 & 0 & 0 & 0 \\
\hline & 1 & 1 & 1 & 1 & 0 & 0 \\
\hline$-E$ & 1 & 0 & 0 & 1 & $E$ & $-2 \mathrm{E}$ \\
\hline & 0 & 1 & 1 & 1 & $-E$ & 0 \\
\hline & 0 & 1 & 0 & 0 & $-E$ & 0 \\
\hline$-2 \mathrm{E}$ & 1 & 1 & 0 & 1 & 0 & $-2 \mathrm{E}$ \\
\hline & 0 & 0 & 0 & 1 & 0 & $-2 E$ \\
\hline$-3 \mathrm{E}$ & 0 & 1 & 0 & 1 & $-E$ & $-2 E$ \\
\hline
\end{tabular}

\begin{tabular}{|c|c|c|c|c|c|c|}
\hline $\begin{array}{c}\text { Output } \\
\text { Voltage }\end{array}$ & \multicolumn{5}{|c|}{ Switching State } \\
Van & \multicolumn{7}{|c|}{ S31 } & S12 & S32 & Vh1 & Vh2 \\
\hline & S11 & S3 & & & & \\
\hline $3 \mathrm{E}$ & 1 & 0 & 1 & 0 & E & $2 \mathrm{E}$ \\
\hline
\end{tabular}

\section{Test system}

Single line diagram of the test system for DSTATCOM is shown in Fig. 5 and the test system employed to carry out the simulations for DSTATCOM is shown in Fig.6 Such system is composed by a $13 \mathrm{kV}, 60 \mathrm{~Hz}$ generation system, feeding two transmission lines through a 3-winding transformer connected in $\mathrm{Y} / \Delta / \Delta, 13 / 115 / 15$ $\mathrm{kV}$. Such transmission lines feed two distribution networks through two transformers connected in $\Delta / \mathrm{Y}, 15 / 11 \mathrm{Kv}$.

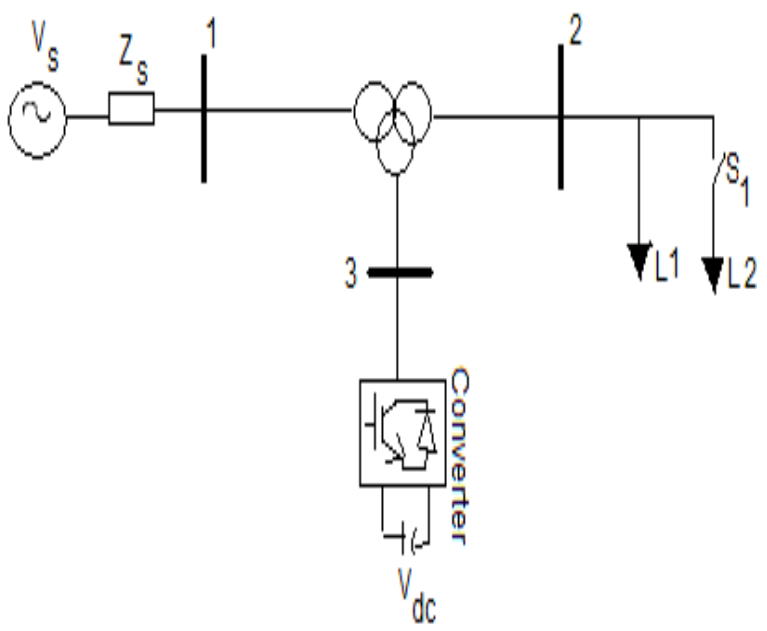

Fig 5: Single line diagram of DSTATCOM 


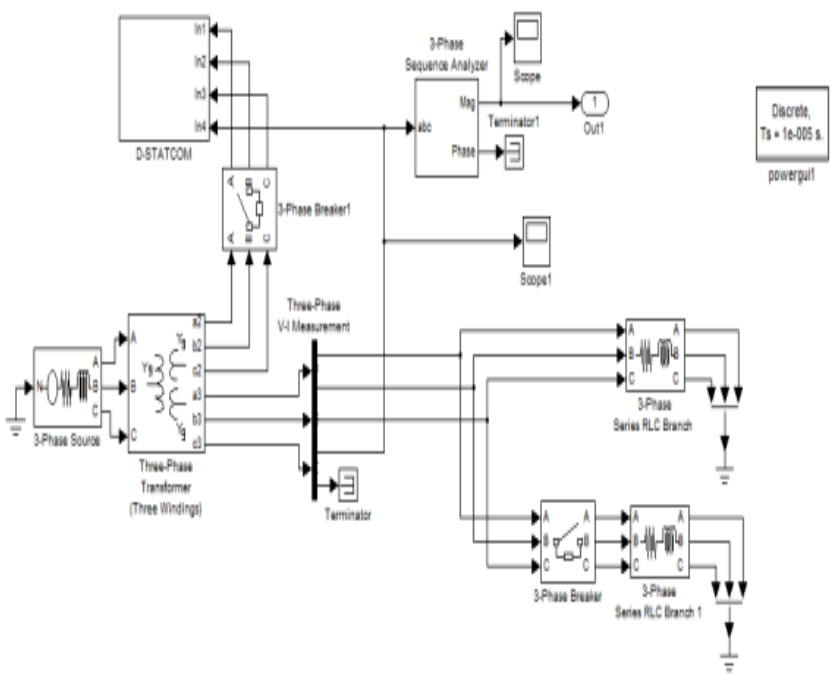

Fig 6: Simulink model of DSTATCOM

To verify the working of a DSTATCOM employed to avoid voltage sags during short-circuit, an additional load is switched on for $100 \mathrm{msec}$. The capacity of the dc storage is $5 \mathrm{KV}$. Using facilities available in MATLAB/SIMULINK the DSTSATCOM is simulated to be in operation only for the duration of the fault as it is expected to be the case in practical situation. Power System Bock set for the use with MATLAB/SIMULINK is based on state-variable analysis and employs either variable or fixed integration-step algorithms.

Fig.6 shows the simulink model of the test system for DSTATCOM.

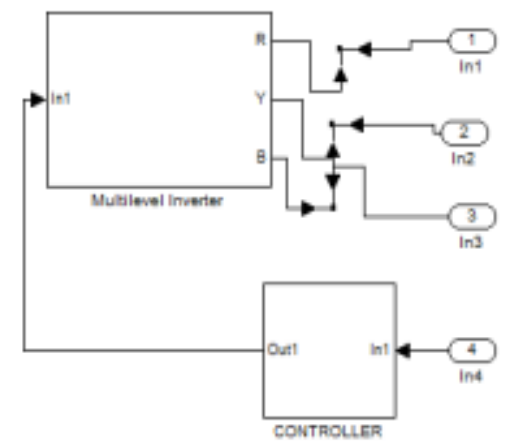

Fig 7: Subsystem of DSTATCOM.

Fig.7 shows the subsystem of DSTATCOM. The reference control signals are generated considering the phase angle jump $\delta$ for 7-level MLI. The phase shifted pulse width modulation for single phase is shown in Fig.4.

\section{Results}

The first simulation contains no DSTATCOM and a single line to ground fault is applied at point A in Fig.8 via a fault resistance of $0.2 \square$, during the period $500900 \mathrm{~ms}$. The voltage sag at the load point is $30 \%$ with respect to the reference voltage. The second simulation is carried out using the same scenario as above but now with the DSTATCOM in operation. The total simulation period is $1400 \mathrm{~ms}$.

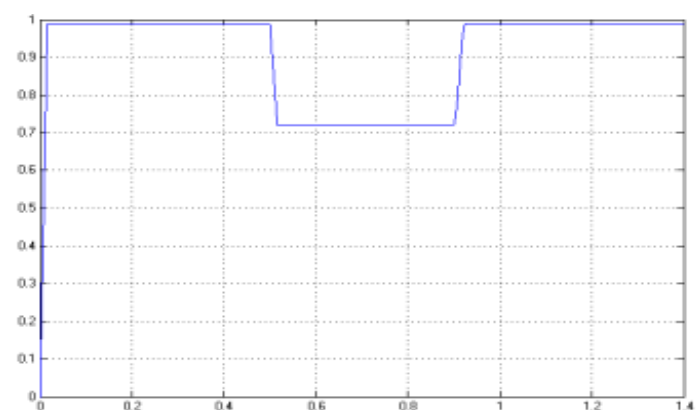

Fig 8: Load Voltage without DSTATCOM-voltage sag for 10

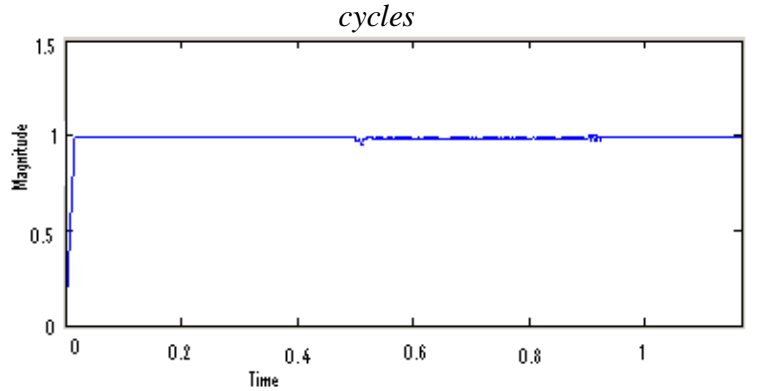

Fig 9. Load voltage 5-level DSATCOM

With isolated dc voltage of $5.87 \mathrm{KV}$

When the 7-level (cascaded H-bridge inverter) DSTATCOM is in operation the voltage sag is mitigated almost completely, and r.m.s voltage at the sensitive load point is maintained at $98 \%$ as shown in Fig.9. The total harmonic distortion is maintained at $0.57 \%$ at the load end.

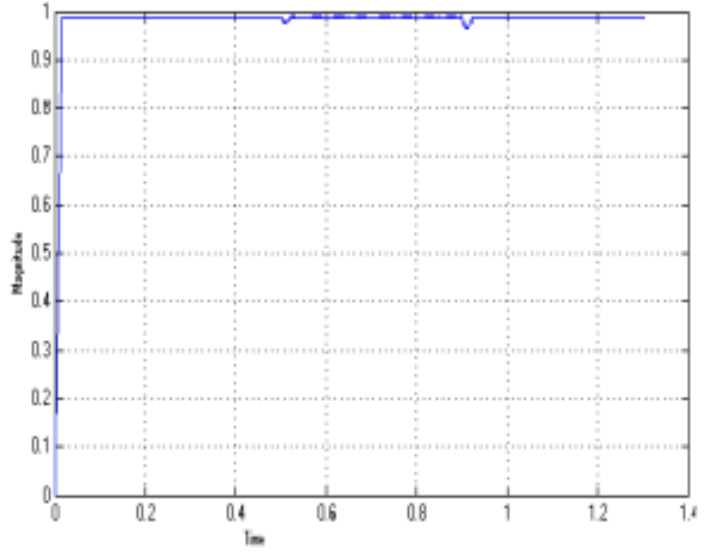

Fig 10: Load voltage 7-level DSATCOM with isolated DC of $3.25 \mathrm{KV}$.

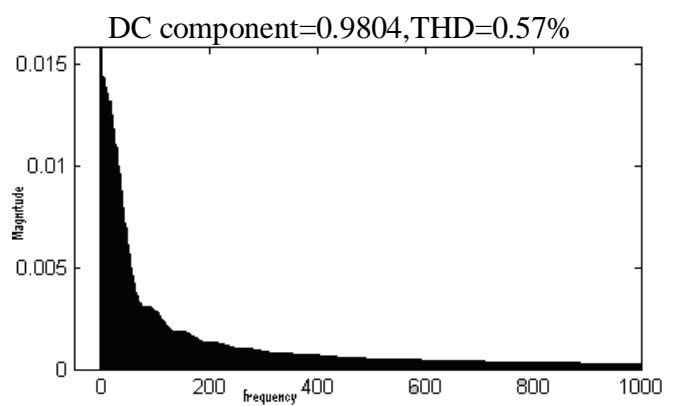

Fig 11: THD of LOAD VOLTAGE for 7-level MLI DSTATCOM 


\section{Conclusions}

The cascaded 7-level inverter topology has been presented for shunt active power filter (DSTATCOM). The advanced pulse width modulation technique (PSPWM) is used for level inverter. The advantages of cascaded inverter in modeling of DSTATCOM are presented clearly. The THD in 7-level inverter is less compared to 5 level inverter, 7-level inverter. The following observations are made based on simulation results.

1) With cascaded multilevel inverter $\mathrm{dc}$ voltage requirement can be reduced, i.e. with low dc voltage higher ac voltages can be produced.

2) As dc voltage requirement is less, the proposed topology is more economical.

3) . Filter at the output of the inverter can be eliminated with multilevel topology further reducing the cost of the filter.

4) The total harmonic distortion is well within the acceptable limits.

\section{References}

[1] Al-Hadidi and Menzies. "Investigation of a cascaded multilevel inverter as an STATCOM". IEEE. Power Eng. Soc. General Meeting.2003, July 3-17,1:193193.DOI:10.1109/PES 2003.1267164.

[2] SNV Ganesh, Ramesh reddy and B V

Shankar ram, "A Neuro control strategy for cascaded multilevel inverter based DYNAMICVOLTAGE RESTORER", IJEPE,2009, Medwell journals.

[3] E.Acha,M.Madrigal.,"Modelling of custom power equipment using Harmonic Domain techniques" ,IEEE,2000 ,PP:264270.

[4]R.Mienski., "Shunt compensation for power quality improment using a TATCOM controller: modeling and simulation”, IEEE. proc. Gener .tran.distib.,151:2.

[5] Kazmier Koloski and Malesani,. "Current control techniques for three phase voltage source pwm converters.A Survey" IEEE.Trans. Ind.Elect., 1998,45(5): 691-03.DOI:10.1109/41720325.

[6] Loh et al, a,b "Reduced common mode carrier - based modulation strategies for cascaded multi level inverters".IEEE.37th IAS Ann .Meeting, 3:20022009.DOI:10.10. 109/IAS.2002.1043807.

[7] Rendusara et al "Analysis of common mode voltage-neutral shift In medium voltage PWM adjustablespeed Drives (MVASD) systems". IEEE.Trans. power Elect, 2000, 15:1124-1133. DOI: 10 1109/63 892827.

[8] $\mathrm{Z}$ hang et alMulti level inverter modulation schemes to eliminate common-mode voltages.IEEE.Trans. 2000, Ind Appl 36:1645-1653 DOI:10 1109/28 887217.

[9] Corzine K A "A hysteresis current-regulated control for multi -level devices” IEEE Trans. Energy conv,2000, 15:169-175 DOI:10 1109160866995.

[10]Buso et al "A dead beat adaptive hysteresis current control" IEEE. Trans.Ind Appl,2000, 36:1174- 1180.DOI:10 1109/28 85597. 